\title{
Rethinking our physics heroes
}

As we reassess the contributions of the 'great people' of science, we should also celebrate the impact of mentors.

t seems to be a human instinct to create hero figures and attach the status of celebrity to those who we feel have accomplished great things. In this respect, physics is no different from the rest of society, as scientists have a tendency to put those who make the biggest breakthroughs on a pedestal.

However, this canonization of those who do great work raises important questions about how we should assign value and credit, and what we should expect of ourselves and others when parsing the more negative behaviour of some of physics' biggest heroes.

There are many high-profile examples of people who created great science but also had problematic aspects to their personalities. For example, recent revelations contained in Albert Einstein's travel diaries show that he seems to have been guilty of stereotyping his Chinese hosts in rather crude terms. Earlier this year, what would have been the 100th birthday of Richard Feynman (pictured, right) was marked by a flurry of celebratory articles and events -

but it was also a reminder of the undoubted sexism he displayed on numerous occasions. Against the backdrop of the \#MeToo campaign that took off in late 2017, other more recent (and often egregious) examples of misconduct in scientific laboratories and institutions have rightfully been highlighted.

Historically, one response to this has been to advocate a focus on the grand discoveries that great scientists achieved, and to leave personality out of the equation. Good science, the argument goes, stands on its own and in some sense is morally neutral in itself. However, this has serious problems associated with it. Most importantly, the victims of harassment and discrimination are naturally silenced in this approach: if the actions of the harasser don't matter then the stories and experiences of the victim don't either.

Simply writing off negative attitudes of our historical heroes as being 'of their time' also seems misguided. Many would claim that, despite (and perhaps because of) its dubious past, modern science could set an example for dealing with these issues in an open and honest way.

But there is another unintended consequence that, while less serious, is also detrimental. There are also a lot of physicists who have kind, caring and constructive

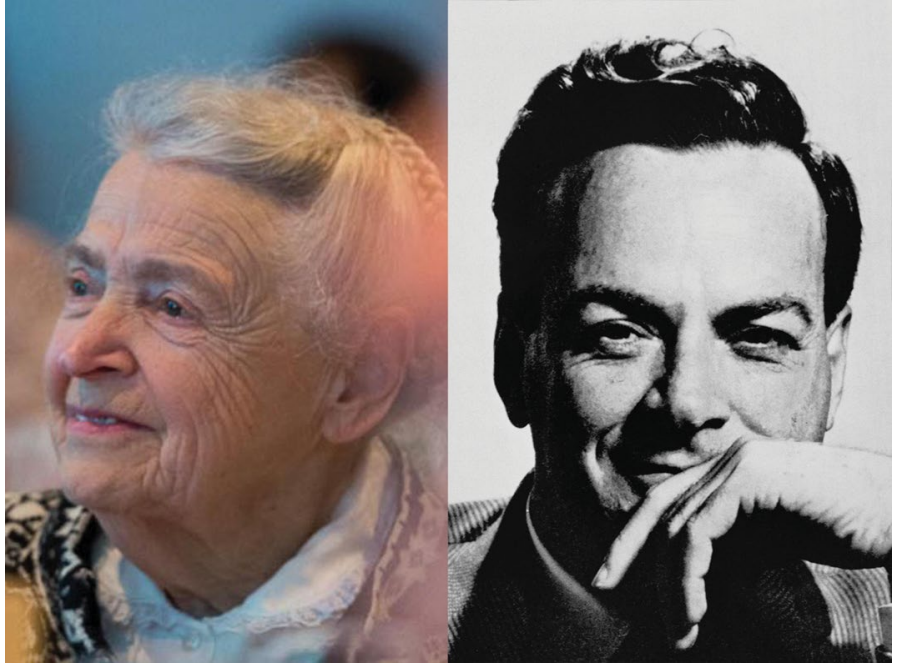

Credit: Nature and Science/Alamy Stock Photo (left), Age fotostock/Alamy Stock Photo (right)

aspects of their character. Removing the personality of a scientist from consideration also minimizes the fact that there are individuals that deserve to be celebrated for the positive impact that they have had on the community.

There are some high-profile examples of this. By all accounts, Mildred Dresselhaus (pictured, left) was a wonderful mentor, continually advocating for other women in science, and apparently always having time to speak with junior researchers and offer advice. Similarly, Sam Edwards was described by his colleagues as someone who showed humility when dealing with those more junior than him and grit when pushing against administrative or established interests.

On a more personal level, many physicists can point to a mentor or advisor who, at some point during their early career, took them under their wing and helped them become the researcher they are today. It's often true that such mentors are not even our official supervisors or those who guide us in the details of our science. Coffeeroom conversations are hugely valuable, covering the politics of the department, tips for writing successful grant applications, suggestions of who to ask about a particular problem, or how to balance professional and personal responsibilities. These mentors should be celebrated for the vital role they play in nurturing the next generation of scientific talent.

No person is entirely good or entirely bad. Therefore, it would be admirable if scientists were able to take a leading role in showing the rest of society that it is possible to balance the positive with the negative, and find a way to reach an honest assessment of the complexity of human personality, while also drawing a line at what is unacceptable.

Perhaps the way we look up to the great people of science needs tweaking. In addition to the necessary and important attempts to bring negative behaviour by those in powerful positions to light, and to make sure that universities enforce their codes of conduct with integrity, we should also actively look to highlight and celebrate those in science who are constructive and generous with their time and energy. They might not be heroes by the commonly accepted meaning of the term, but they arguably have more impact on those near them than the traditional icons of science. We could also tweak our personal aspirations: maybe our aim should be to act more like heroic role models rather than heroic researchers.

Published online: 2 August 2018 https://doi.org/10.1038/s41567-018-0263-0 